Central European Journal of Energetic Materials, 2016, 13(1), 261-270

ISSN 1733-7178

e-ISSN 2353-1843

\title{
Explosion Parameters of Gaseous JP-10/Air Mixtures
}

\author{
Qi ZHANG* and Xueling LIU**
}

State Key Laboratory of Explosion Science and Technology, Beijing Institute of Technology, Beijing 100081, China

E-mail: *qzhang@bit.edu.cn; *fanyanmusic@126.com

\begin{abstract}
This paper describes flammability measurements and data on the missile fuel, JP-10. The measurements include maximum explosion pressure, maximum rate of pressure rise and limiting flammability concentrations. Through a series experiments, the influences of the concentration of gaseous JP-10 in air on the explosion pressure and on the rate of explosion pressure rise have been analyzed, and the results are discussed. The explosion pressure of gaseous JP-10/air mixtures reached their highest values within the studied range at a concentration of $1.88 \%$. The variation trends in the explosion pressure and the rate of pressure rise of gaseous JP-10/air mixtures with volume \% appear similar. When the volume $\%$ of gaseous JP-10 lies in the range $0.5-1.8 \%$, the explosion pressure and the rate of pressure rise for gaseous JP-10/air mixtures increase with the volume $\%$, while in the range $1.8-5 \%$ these parameters decrease with the volume $\%$. The flammability limits of gaseous JP-10/air mixtures are near those of gaseous n-decane/air mixtures. However, the maximum explosion pressure and the maximum rate of pressure rise of gaseous JP-10/air mixtures are much higher than those of gaseous n-decane/air mixtures.
\end{abstract}

Keywords: JP-10, fuels, decane, explosion pressure, explosible limits

\section{Introduction}

JP-10 is essentially a pure component: exo-tetrahydrodicyclopentadiene. It has an appreciable density $\left(0.94 \mathrm{~g} / \mathrm{cm}^{3}\right)$, a very high boiling point $\left(187^{\circ} \mathrm{C}\right)$, a very low freezing point of the fluid $\left(-79^{\circ} \mathrm{C}\right)$, and a high volumetric energy density [1-3]. Because of the importance of JP-10 fuel in Pulse Detonation Engine (PDE) applications, a comprehensive study of flame acceleration and deflagration to detonation transition (DDT) in JP-10 liquid drop/air mixtures was performed [4]. 
Although many research studies on JP-10 liquid drop/air [5-20] explosion and gaseous JP-10/air detonation [21] have been carried out, very little explosibility information on gaseous JP-10/air mixtures is available in the literature.

Knowledge of the characteristics of the explosion of gaseous JP-10/air mixtures is an important prerequisite for its proper use. Consequently, in this work, we have used an explosibility measurement system consisting of a $5 \mathrm{~L}$ explosion vessel and a transient pressure measurement sub-system. Through a series of experiments carried out in this system, the influence of the concentration of gaseous JP-10 on the explosion pressure and on the rates of explosion pressure rise have been analyzed and discussed, and the explosible limits of gaseous JP-10/air mixtures have been studied.

\section{Experimental Apparatus and Procedures}

\subsection{General}

The experimental arrangement used in this study consisted of a $5 \mathrm{~L}$ cylindrical vessel coupled with an electric ignition system and a data acquisition system, as shown in Figure 1. Experiments were performed in the cylinder explosion vessel with central ignition. The height $h$ of the vessel was $340 \mathrm{~mm}$ and the inner diameter $2 R$ was $160 \mathrm{~mm}$. In the experimental vessel, ignition was achieved by means of an inductive-capacitive spark produced between stainless steel electrodes with rounded tips, separated by a spark gap of $1 \mathrm{~mm}$. The electrode diameter used in the experiments was $1 \mathrm{~mm}$.

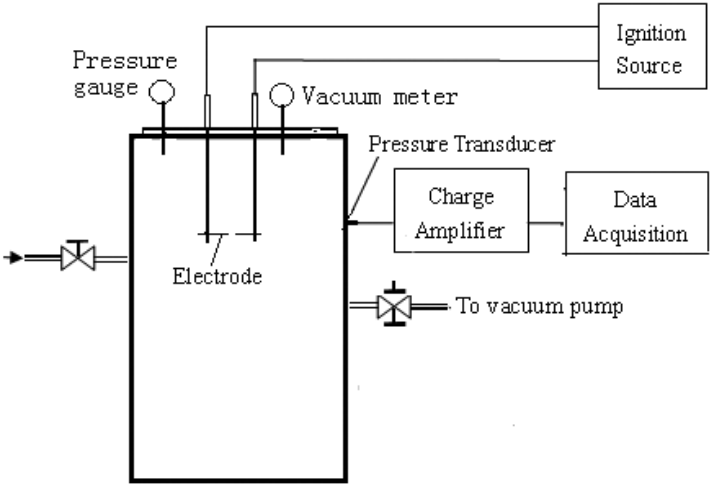

Figure 1. Cylindrical vessel and experimental arrangement. 


\subsection{Explosion pressure}

Explosions were monitored by means of a Kistler pressure transducer mounted on the wall of the experimental vessel. All of the results were stored through a data acquisition device. The data acquisition system was triggered by the control unit, and recorded the pressure data individually at a sampling frequency of $1 \mathrm{MHz}$.

\subsection{Spark ignition energy}

The ignition energy can be easily determined on the basis of the given capacitance and applied voltage through a simple calculation. The general relationship is expressed as:

$$
E=\frac{1}{2} C U^{2}
$$

where: $C$ is the capacitance of the capacitor, $U$ is the voltage of the capacitor discharge, and $E$ is the energy stored in the capacitor, which is traditionally regarded as the ignition energy.

\subsection{Experimental procedure}

For gaseous JP-10/air mixtures, the JP-10 concentrations were evaluated from the volume of the experimental vessel. A measured amount of liquid JP-10 was withdrawn, weighed by means of an electronic balance, and then placed in the experimental vessel. Subsequently, heating the outer surface of the vessel to the specified temperature $\left(180^{\circ} \mathrm{C}\right)$ vaporized all of the JP-10 therein, which was necessary since the vapour pressure of JP-10 under normal atmospheric conditions is too low to reach explosive vapour concentrations. The vessel containing the liquid JP-10 had to be heated for $30 \mathrm{~min}$ to achieve vaporization. The gaseous mixture was stirred for $1 \mathrm{~min}$ and then left to become homogeneous and quiescent for a further $1 \mathrm{~min}$ before ignition. The gaseous JP-10/air mixture was then ignited by an electric spark generated by a spark generator. After ignition occurred within the gaseous mixture, an explosion wave formed and propagated from the position of ignition to the wall of the vessel. The pressure history resulting from the gaseous JP-10/air mixture explosion was recorded by the pressure transducer connected to the data acquisition system. Finally, the values $(\mathrm{d} p / \mathrm{d} t)_{\max }$ of the derivatives of the pressure with respect to time were obtained on the basis of the experimental recordings of the pressure $p(t)$. It should be noted that the rates of pressure rise change with time and the $(\mathrm{d} p / \mathrm{d} t)_{\max }$ value denotes their maximum values in the wave front slope for a given pressure history. As such, the pressure changes with time describe a given pressure history, and the maximum pressure represents the peak value of a given pressure wave. 


\section{Experimental Results}

\subsection{Explosion parameters of gaseous JP-10}

A series of tests of gaseous JP-10/air mixture explosions with an ignition energy of $10.24 \mathrm{~J}$, were carried out.

In the experiments, the environmental conditions were as follows: relative humidity $40 \%$, and the initial temperature and pressure of the gaseous JP-10/air mixture were $180{ }^{\circ} \mathrm{C}$ and $0.0032-0.0033 \mathrm{MPa}$, respectively.

The flammability limits of gaseous JP-10 in air were determined as $0.5-5 \%$. Typical results of the pressures recorded in the experiments are shown in Figure 2, in which the curves correspond to the cases of volume \%s of gaseous JP-10 of $0.5,0.94,1.48,1.88,3.13$ and 5\%. The experimental results are listed in Table 1.

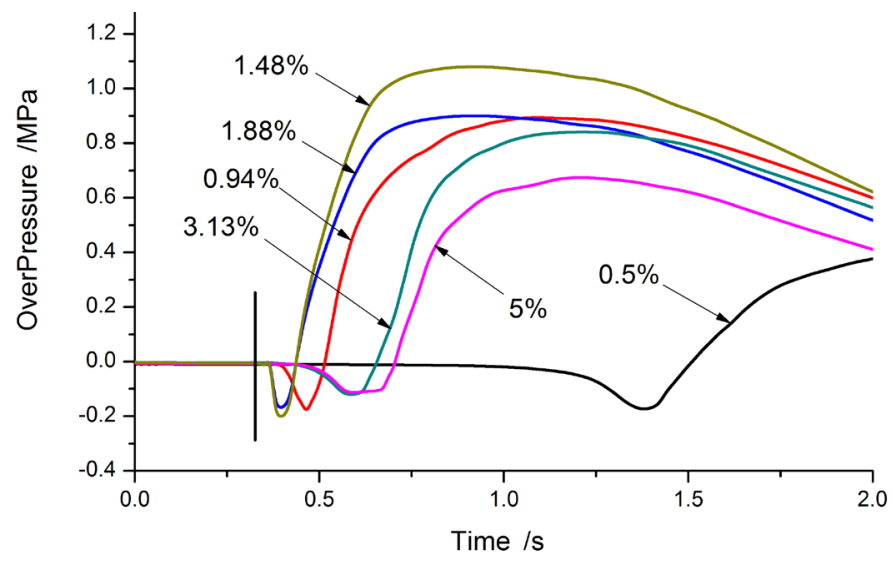

Figure 2. Explosion pressures of gaseous JP-10/air mixtures at different concentrations of JP-10.

For a given volume $\%$ of gaseous JP- 10 in air, the measured pressure changed with time; it gradually increased from the initial value to a peak value, the peak value being defined as the maximum pressure. The maximum pressure varied with the volume $\%$ of gaseous JP-10. The rate of pressure rise varied with the volume $\%$ of gaseous JP- 10 . The highest rate of pressure rise denotes the highest value obtained within the examined concentration range. The maximum rate of pressure rise denotes the maximum value obtained within the examined range for a given pressure wave.

The data listed in Table 1shows that the maximum explosion pressure reached its highest value at a volume $\%$ of gaseous JP-10 of $1.48 \%$. When the volume $\%$ of gaseous JP-10/air mixtures was lower than $0.5 \%$ or higher than 
$5 \%$, explosion was not initiated by the ignition energy of $10.24 \mathrm{~J}$. Therefore, the lower explosible limit of gaseous JP-10 in air is $0.5 \%$ and the upper explosible limit is $5 \%$, under the test conditions used in this study.

Table 1. Experimental results on the explosion of gaseous JP-10/air mixtures

\begin{tabular}{|c|c|c|}
\hline $\begin{array}{c}\text { Volume \% of gaseous JP-10 } \\
{[\%]}\end{array}$ & $\begin{array}{c}\text { Maximum pressure } \\
{[\mathrm{MPa}]}\end{array}$ & $\begin{array}{l}(\mathrm{d} p / \mathrm{d} t)_{\max } \\
{\left[\mathrm{MPa} \cdot \mathrm{s}^{-1}\right]}\end{array}$ \\
\hline 0.31 & no ignition in three tests & \\
\hline 0.47 & no ignition in three tests & \\
\hline 0.50 & 0.38 & 1.35 \\
\hline 0.50 & 0.36 & 1.35 \\
\hline 0.50 & 0.35 & 1.34 \\
\hline 0.94 & 0.89 & 5.4 \\
\hline 0.94 & 0.85 & 5.2 \\
\hline 0.94 & 0.87 & 5.3 \\
\hline 1.48 & 1.08 & 5.6 \\
\hline 1.48 & 1.06 & 5.5 \\
\hline 1.48 & 0.99 & 5.3 \\
\hline 1.88 & 0.90 & 4.3 \\
\hline 1.88 & 0.88 & 4.0 \\
\hline 1.88 & 0.89 & 4.2 \\
\hline 3.13 & 0.84 & 4.4 \\
\hline 3.13 & 0.82 & 4.1 \\
\hline 3.13 & 0.80 & 4.0 \\
\hline 5.00 & 0.67 & 3.64 \\
\hline 5.00 & 0.62 & 3.42 \\
\hline 5.00 & 0.65 & 3.55 \\
\hline 5.31 & no ignition in three tests & \\
\hline 5.63 & no ignition in three tests & \\
\hline 6.25 & no ignition in three tests & \\
\hline
\end{tabular}

The explosion pressures were higher at volume $\%$ s of 0.94 and $1.88 \%$, and the deviations in the measured data were also larger at these volume \%s. The variation trend of the rate of pressure rise for the explosion of gaseous JP-10/air mixtures with volume \% was similar to those of the explosion pressure, and the rate of pressure rise reached its highest value at a volume $\%$ of $1.48 \%$. The deviations in the measured data were larger at volume \%s of 0.94 and $1.88 \%$.

The chemical reaction for the gaseous JP-10/air mixtures with the stoichiometric volume $\%$ is: 


$$
\mathrm{C}_{10} \mathrm{H}_{16}+14\left(\mathrm{O}_{2}+\frac{79}{21} \mathrm{~N}_{2}\right)=8 \mathrm{H}_{2} \mathrm{O}+10 \mathrm{CO}_{2}+14 \times \frac{79}{21} \mathrm{~N}_{2}
$$

The stoichiometric volume \% of gaseous JP-10 /air mixture is:

$$
C_{s t}=\frac{1}{1+14\left(1+\frac{79}{21}\right)}=1.48 \%
$$

The equation above illustrates that the peak explosion pressure of the gaseous $\mathrm{JP}-10 /$ air mixtures reaches its maximum value at $1.48 \%$ volume $\%$ in theory. In the actual chemical reaction, it is impossible for all of the elements $\mathrm{C}$ and $\mathrm{H}$ in the mixture to be oxidized to $\mathrm{CO}_{2}$ and $\mathrm{H}_{2} \mathrm{O}$. In fact when the chemical reaction reaches a balanced state, $\mathrm{CO}, \mathrm{H}_{2}$ and $\mathrm{OH}$ are always contained in the products. Consequently, the volume $\%$ at which the peak explosion pressure of the combustible gas/air mixtures reaches its maximum value is always slightly more than that in the stoichiometric state. In these experiments, the peak explosion pressures of the gaseous JP-10/air mixtures reached their maximum value at volume $\% 1.48 \%$. The above analysis shows that the measuring system and the experimental results in this work are validated.

\subsection{Comparison with n-decane}

For comparison with JP-10, the explosion parameters of gaseous n-decane/air mixtures were measured under the same experimental conditions. The typical explosion pressure histories are shown in Figure 3. The experimental results are listed in Table 2.

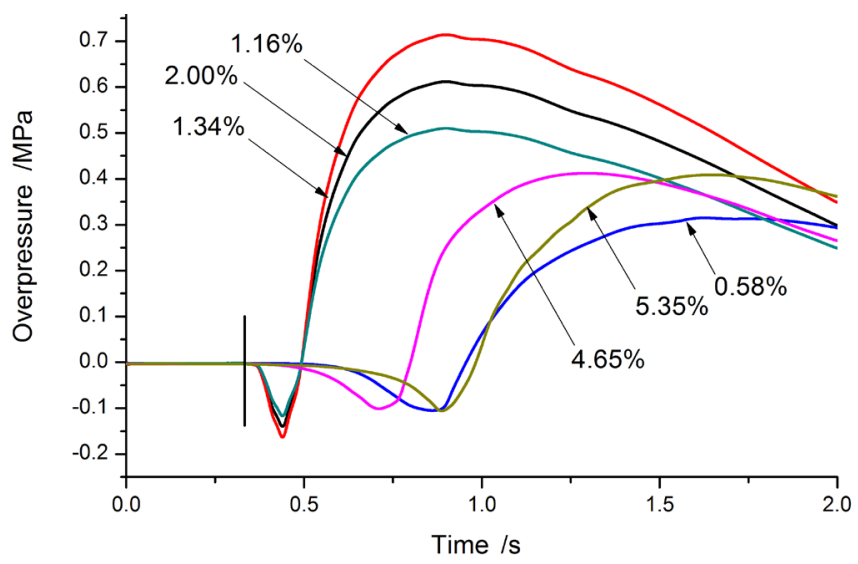

Figure 3. Explosion pressures of gaseous n-decane/air mixtures at different concentrations of n-decane. 
Table 2. Experimental results on the explosion of gaseous n-decane/air mixtures

\begin{tabular}{|c|c|c|}
\hline Volume $\%$ & $\begin{array}{c}\text { Average maximum pressure } \\
{[\mathrm{MPa}]}\end{array}$ & $\begin{array}{c}\text { Average }(\mathrm{dp} / \mathrm{dt})_{\max } \\
{\left[\mathrm{MPa} \cdot \mathrm{s}^{-1}\right]}\end{array}$ \\
\hline 0.55 & no ignition in three tests & \\
\hline 0.58 & 0.31 & 1.11 \\
\hline 1.16 & 0.51 & 4.08 \\
\hline 1.34 & 0.72 & 5.13 \\
\hline 2 & 0.61 & 3.92 \\
\hline 4.65 & 0.41 & 2.58 \\
\hline 5.35 & 0.40 & 1.48 \\
\hline 5.32 & no ignition in three tests \\
\hline
\end{tabular}

The data in Table 2 show that the maximum explosion pressure of gaseous n-decane was at volume $\% 1.34 \%$.

The chemical reaction of gaseous n-decane/air mixtures with the stoichiometric volume $\%$ is:

$$
\mathrm{C}_{10} \mathrm{H}_{22}+15.5\left(\mathrm{O}_{2}+\frac{79}{21} \mathrm{~N}_{2}\right)=11 \mathrm{H}_{2} \mathrm{O}+10 \mathrm{CO}_{2}+15.5 \times \frac{79}{21} \mathrm{~N}_{2}
$$

The stoichiometric volume \% of a gaseous n-decane/air mixture is:

$$
C_{s t}=\frac{1}{1+15.5\left(1+\frac{79}{21}\right)}=1.34 \%
$$

The theoretical result agrees with the measured data.

For every explosion experiment, the mass of fuel in the explosion vessel was known. Based on the experimental results, the variation of the explosion pressure with the mass of fuel was obtained. A comparison of the explosion pressures from gaseous JP-10/air and gaseous n-decane/air, under the conditions of the same mass, is shown in Figure 4. 


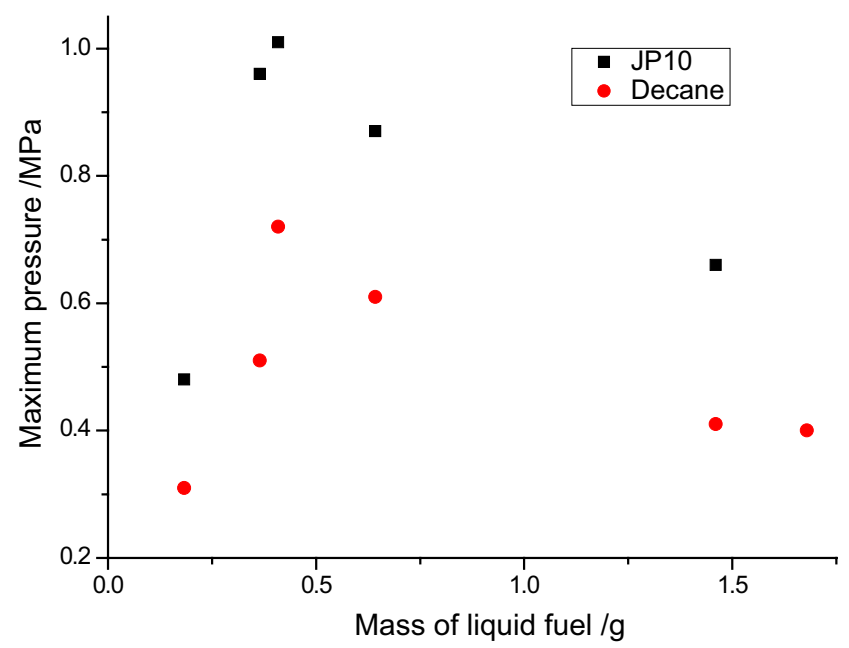

Figure 4. Comparison of the explosion pressures between gaseous JP10/air and gaseous n-decane/air at the same mass.

Figure 4 shows that the explosion pressures from gaseous JP-10/air are higher than those of gaseous $n$-decan/air for the same mass. The combustion heat of $\mathrm{n}$-decane is $47.39 \mathrm{~kJ} / \mathrm{kg}$, and that of JP-10 is $42.4 \mathrm{~kJ} / \mathrm{kg}$. The former is higher than the latter. Based on the combustion heats of both fuels, the explosion pressure n-decane/air should be higher. This is contrary to the experimental results. In fact, the explosion process is different from that of combustion. Combustion heat is the energy released by the chemical reaction of fuel in air at constant pressure, whilst for an explosion it is at constant volume. Therefore, the explosion pressure of the fuel with the higher combustion heat may not necessarily be higher. Compared with n-decane, gaseous JP-10 in air has better explosibility.

\section{Conclusions}

We have studied the explosion behaviour of gaseous JP-10/air mixtures in a confined vessel. The main conclusions drawn can be summarized as follows. 1. The explosion pressures of gaseous JP-10/air mixtures attained their highest value at a gaseous JP-10 concentration within the studied concentration range of $1.48 \%$.

2. The variation trends in the explosion pressure and the rate of pressure rise of gaseous JP-10/air mixtures with volume \% appear similar. When the volume $\%$ of gaseous JP-10 lies in the range $0.5-1.48 \%$, both the explosion 
pressure and the rate of pressure rise with increasing volume $\%$, whereas for volume $\%$ s in the range $1.48-5 \%$ they decrease with increasing volume $\%$.

3. The maximum explosion pressure of gaseous n-decane reached its highest value at a volume $\%$ of $1.34 \%$. Compared with n-decane, gaseous JP-10 in air has better explosibility.

\section{Acknowledgments}

The research presented in this paper was supported by the National Science Foundation of China (11372044).

\section{References}

[1] Bruno T.J., Huber M.L., Laesecke A., Lemmon E.W., Perkins R.A., Thermochemical and Thermophysical Properties of JP-10, NISTIR 6640, 2006.

[2] Osmont A., Gokalp I., Evaluating Missile Fuels, Propellants Explos. Pyrotech., 2006, 31, 343-354.

[3] Jiao C.Q., DeJoseph Jr. C.A., Garscadden A., Dissociative Ionization of JP-10 $\left(\mathrm{C}_{10} \mathrm{H}_{16}\right)$ by Electron Impact, Int. J. Mass Spectrom., 2007, 266, 92-96.

[4] Card J., Rival D., Ciccarelli G., DDT in Fuel-air Mixtures at Elevated Temperatures and Pressures, Shock Waves, 2005, 14, 167-173.

[5] Park S.H., Kim J., Chun H.J., Chung W., Kim S.G., Lee C.H., Chun B.H., Han J. S., Hun J.B., Han H., Kim S.H., Metal Effects on the Thermal Decomposition of Exotetrahydrodicyclopentadiene, Ind. Eng. Chem. Res., 2013, 52, 4395-4400.

[6] Chenoweth K., van Duin A.C.T., Dasgupta S., Goddard W.A., Initiation Mechanisms and Kinetics of Pyrolysis and Explosion of JP-10 Hydrocarbon Jet Fuel, J. Phys. Chem. A, 2009, 113, 1740.

[7] Peters J.E., Mellor A.M., Liquid Fuel Spray Ignition Predictions for JP-10, J. Energy, 1982, 7, 95-96.

[8] Antaki P., Williams F.A., Observations on the Explosion of Boron Slurry Droplets in Air, Combust. Flame, 1987, 67, 1-8.

[9] Clausen L.C., Li T.X., Law C.K., Effects of Additives on the Micro Explosion of Carbon Slurry Droplets, J. Propuls. Power, 1988, 4, 217-221.

[10] Wong S.C., Lin A.C., Micro explosion Mechanisms of Aluminum/Carbon Slurry Droplets, Combust. Flame, 1992, 89, 64-76.

[11] Green G.J., Takahashi F., Walsh D.E., Dryer F.L., Aerodynamic Device for Generating Mono-disperse Fuel Droplets, Rev. Sci. Instrum., 1989, 60, 646-52.

[12] Davidson D.F., Horning D.C., Herbon J.T., Hanson R.K., Shock Tube Measurements of JP-10 Ignition, Symp. Int. Combust., 2000, 28, 1687-1692.

[13] Li S.C., Varatharajan B., Williams F.A., Chemistry of JP-10 Ignition, AIAA J., 2001, 39, 2351-2356. 
[14] Austin J.M., Shepherd J.E., Detonations in Hydrocarbon Fuel Blends, Combust. Flame, 2003, 132, 73-90.

[15] Varatharajan B., Petrova M., Williams F.A., Tangirala V., Two-step Chemicalkinetic Descriptions for Hydrocarbon-oxygen-diluent Ignition and Detonation Applications, Proc. Combust. Inst., 2005, 30, 1869-1876.

[16] Nakra S., Green R.J., Anderson S.L., Thermal Decomposition of JP-10 Studied by Micro-flowtube Pyrolysis-Mass Spectrometry, Combust. Flame, 2006, 144, 662-674.

[17] Nageswara Rao P., Kunzru D., Thermal Cracking of JP-10: Kinetics and Product Distribution, J. Anal. Appl. Pyrolysis, 2006, 76, 154.

[18] Devener B.V., Anderson S.L., Breakdown and Explosion of JP-10 Fuel Catalyzed by Nanoparticulate $\mathrm{CeO}_{2}$ and $\mathrm{Fe}_{2} \mathrm{O}_{3}$, Energy Fuels, 2006, 20, 1886-1894.

[19] Tangirala V., Benkiewicz K., Koichi Hayashi A., Tsuboi N., Numerical Simulation of JP-10/Air Two-phase Detonation, Int. J. Energ. Mater. Chem. Propuls., 2008, 7, 421-436.

[20] Liu X., Wang Y., Zhang Q., A study of the Explosion Parameters of Vapor-liquid Two-phase JP-10/Air Mixtures, Fuel, 2016, 165, 279-288.

[21] Liu L., Zhang Q., Shen S., Li D., Lian Z., Wang Y., Evaluation of Detonation Characteristics of Aluminum/JP-10/Air Mixtures at Stoichiometric Concentrations, Fuel, 2016, 169, 41-49. 